\title{
Multispectral aerial photography as a supplemental technique in agricultural research
}

\author{
J. G. P. W. Clevers
}

Department of Landsurveying and Remote Sensing, Wageningen Agricultural University, P.O. Box 339, NL 6700 AH Wageningen, Netherlands

Received 26 February 1987; accepted 26 August 1987

Key words: remote sensing, multispectral aerial photography, reflectance, leaf area index

\begin{abstract}
For monitoring crop growth and development, remote sensing techniques offer great possibilities. Narrow spectral bands in the visible and near infrared region of the electromagnetic spectrum are promising for application in agricultural research. In this paper, attention is focussed on the application in agricultural field trials. By using an airborne multispectral photographic (MSP) system, recordings of high spectral resolution were obtained through a judicious choice of films and filters (25-100 $\mathrm{nm}$ bandwidth). By using equipment which was easily available and by selecting an appropriate densitometer, recordings were obtained with a high temporal (fortnightly) and sufficient spatial resolution (in the order of $1 \mathrm{~m}^{2}$ ). Calibrated reflectance factors of crops were obtained by applying a procedure for atmospheric correction and radiometric calibration using reference targets in the field. The system was tested in field trials at the experimental farm of the Agricultural University Wageningen. Spectral reflectance characteristics of cereals were obtained during the growing season in a green, red and infrared band for several treatments (e.g. nitrogen nutrition, sowing date). Subsequently, the leaf area index was estimated by using these reflectance factors. The main result was that quantitative information about crops was obtained in an objective and non-destructive manner with greater precision by MSP than by conventional field sampling methods (e.g. the leaf area index measured by harvesting a sample of the crop).
\end{abstract}

\section{Introduction}

During the past decades, knowledge about remote sensing techniques and their application to areas such as agriculture has improved considerably. Bunnik (1978) described the possibilities of applying optical remote sensing in agriculture, particularly with regard to its relation with crop characteristics such as soil cover, leaf area index (LAI) and dry matter weight. The reflectance factor is a characteristic which can be ascertained by means of remote sensing. This reflectance factor is de- 
fined as the radiance of an object in a certain direction under certain irradiation conditions, relative to the radiance of an ideal, white, diffusing surface, in the same direction and under the same irradiation conditions (Verhoef \& Bunnik, 1975). If reflectance factors are required with high spectral, spatial and temporal resolution for crop monitoring, Clevers (1986a, 1986b) selected black and white multispectral aerial photography. Bunnik (1978) identified three wavelengths, applicable from an aerial platform, based on optimum information about relevant crop characteristics: $550 \mathrm{~nm}$ (green), $670 \mathrm{~nm}$ (red) and $870 \mathrm{~nm}$ (infrared). In the literature there is a certain consensus about this choice.

Systems of aerial photography provide recordings of the reflected visible and infrared radiation. The spectral resolution may be high when adequate films and filters are used in order to achieve a multispectral photographic (MSP) system with narrow bands. The spatial resolution will primarily depend on lens type, altitude, film material and image motion. By using an appropriate microdensitometer or densitometer with small aperture, quantitative measurements with high spatial resolution may be obtained. Moreover, the measurements on the photograph can be carried out at exactly determinable locations of an object. The camera equipment can be installed in small planes if small non-metric cameras are used (e.g. $70-\mathrm{mm}$ aerial photography). Consequently, cost stays within acceptable limits and a high temporal resolution can be obtained. All these considerations render black and white multispectral aerial photography the most promising remote sensing technique for application to small areas.

One specific application of remote sensing is in agricultural field trials, in which it is necessary to carry out observations regularly during the growing season. Conventionally, the agronomist has two possible approaches at his disposal. The first one is a subjective judgement of plots and estimation of plant characteristics, yielding primarily qualitative information. The second one is based on taking samples of a few plants from each plot. This yields quantitative information, because plant characteristics such as LAI or dry matter weight can be measured. The subjective and qualitative nature of the first approach and the destructive sampling of a few plants, resulting in a large variability between measurements, of the second approach are the main disadvantages.

Remote sensing techniques provide quantitative information about a whole field trial instantaneously and non-destructively. The aim of the research presented in this paper was to establish whether remote sensing can support and/or replace conventional field measurements in field trials. Emphasis was on improving precision in field trials.

\section{Methodology}

\section{Aerial photography}

Black and white multispectral aerial photography was carried out by taking vertical photographs at scale 1:8000 from a single-engine aircraft, equipped with Hasselblad cameras with Planar $100 \mathrm{~mm}$ lenses, at intervals of about two weeks. A Minol- 
ta photometer was used for correcting the camera settings for differences in illumination between missions, and the expected reflectance level of the objects was also taken into account for obtaining correct levels of exposure.

Missions were only carried out under nearly constant atmospheric conditions; during a mission, camera settings (exposure time and relative aperture) were not altered for a certain film/filter combination. By a judicious choice of aerial films with satisfactory sensitivity used in combination with filters, the optimal wavelengths identified by Bunnik (1978) were matched: a green band $(555-580 \mathrm{~nm})$, a red band $(665-700 \mathrm{~nm})$ and an infrared band $(840-900 \mathrm{~nm})$ (see Clevers, 1986a). The development of the films was standardized and checked by means of sensitometry.

Densities were measured by means of an automatized Macbeth TD-504 densitometer with an aperture of $0.25 \mathrm{~mm}$. After converting the densities to radiant energy values by means of the characteristic curve (sensitometry), compensation for off-axis imagery was made for each image point (only for light fall-off; vignetting was avoided). There exists a linear relationship between this corrected radiant energy value and the reflectance factor of the object (Slater, 1980; Clevers, 1986a, 1986b). In this linear function the camera calibration (exposure time, relative aperture, transmittance of the optical system) and atmospheric correction (irradiance, path radiance, atmospheric attenuation) were incorporated. Reference targets with known reflectance characteristics (absolute reflectance factors of the targets were measured in the laboratory) were set up in the field during missions and recorded at the same camera setting and under the same atmospheric conditions as the field trials, in order to ascertain the parameters of the linear function. This calibration procedure is schematically illustrated in Fig. 1.

Reflectance factors ascertained in this way with multispectral aerial photography appear to be well calibrated when compared with radiometers in the field (Clevers, 1986 b), supplying information that is only influenced by the object. This allows multitemporal comparison and analysis. Up to now, the calibration had often been a bottle-neck, in particular because of the analog data registration (e.g. Curran, 1980, 1982, 1983; Graham, 1980; Kannegieter, 1980; Ross, 1973; Sievers, 1976).

\section{Test area}

The research was carried out at the Ir A. P. Minderhoudhoeve, experimental farm of the Agricultural University Wageningen (Netherlands), situated in one of the new polders, Oost-Flevoland, which was reclaimed about 30 years ago. The new polders are flat and highly productive agricultural lands with a homogeneous loamy (top)soil.

The usefulness of remote sensing techniques in agricultural research was verified by means of analysing several field trials.

Field trial 116 in 1982. Barley in a split-plot design in three replicates (cultivar 'Trumpf'). Whole-plot treatments were 2 sowing dates: 26 March (Z1) and 22 April (Z2). Split-plot treatments were 6 randomized nitrogen levels: $0,20,40,60,80,100$ $\mathrm{kg} \mathrm{N}$ per ha (N1 to N6). 
J. G. P. W. CLEVERS

MATERIAL AND

INSTRUMENT
MEASURED

VARIABLE
ADDITIONAL

OPERATION

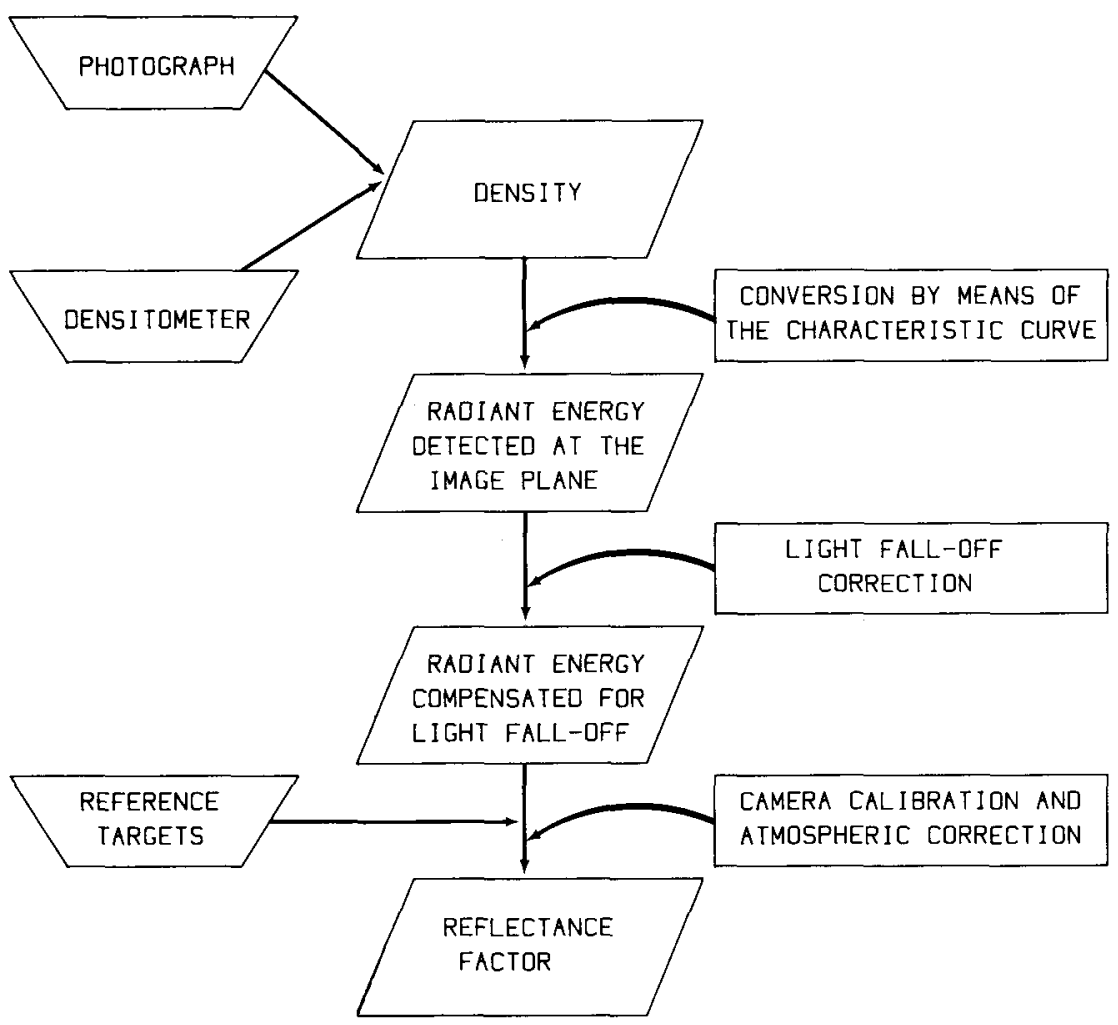

Fig. 1. Flow diagram, illustrating the calibration of aerial photography.

Field trial 116 in 1983. Barley in a split-plot design in four replicates (cultivar 'Trumpf'). Whole-plot treatments were 2 sowing dates: 7 March (Z1) and 21 April (Z2). Split-plot treatments were 5 randomized nitrogen levels (N1 to N5), applied as split dressing (in $\mathrm{kg} \mathrm{N}$ per ha):

\begin{tabular}{lccc}
\hline & before sowing & Feekes stage 7 & total \\
N1 & 0 & 0 & 0 \\
N2 & 20 & 0 & 20 \\
N3 & 20 & 20 & 40 \\
N4 & 20 & 40 & 60 \\
N5 & 20 & 60 & 80
\end{tabular}

For Feekes stages see Large (1954). 
Field trial 92 in 1982. Spring wheat in a split-plot design in three replicates (cultivar 'Bastion', sowing date: 26 March 1982). Whole-plot treatments were 2 fungicide treatments: no fungicides at all (F0) and $4 \mathrm{~kg}$ Bavistin M per ha at Feekes stage 5 combined with 0.5 I Bayleton per ha at stage 10.4 (F1). Split-plot treatments were 2 sowing densities and 4 nitrogen levels, which were completely randomized within the whole plots. The sowing densities were: 150 seeds per $\mathrm{m}^{2}(\mathrm{~S} 1)$ and 300 seeds per $\mathrm{m}^{2}(\mathrm{~S} 2)$. Only results for one nitrogen level will be presented $(20 \mathrm{~kg} N$ per ha before sowing combined with $80 \mathrm{~kg} \mathrm{~N}$ per ha at F8).

\section{Results and discussion}

\section{Spectral reflectance factors}

In field trial 116, in 1982, reflectance factors were ascertained by means of multispectral aerial photography (MSP) in green, red and infrared spectral bands. With MSP, at the Ir A. P. Minderhoudhoeve an area corresponding to about $10 \mathrm{~m}^{2}$ in the field was sampled. The effects for two nitrogen levels for two sowing dates are illustrated in Fig. 2 for all three bands. In this figure the reflectance factors are plotted as a function of days after sowing. The patterns of green and red reflectance factors were similar. The reflectance factors in the visible bands decreased with increasing growth during the beginning of the growing season due to increased absorptance of light by green leaves. On the first recording date ( 28 April), only bare soil was present, resulting in similar reflectance factors in all spectral bands considered. At complete soil cover (about 75 days after sowing for the early-sown crop and 55 days after sowing for the late-sown crop) the reflectance in the visible bands remained fairly constant. At the end of the growing season this reflectance increased due to senescence of the crop. The sowing date effect was evident. The late-sown crop showed a faster development due to higher temperatures during germination and initial growth than the early-sown crop, resulting in a shorter growing season between sowing and harvesting (shift in response). There were negative nitrogen effects on reflectance factors in the visible bands, but the differences were small. For the infrared reflectance factor the shift in response due to sowing date also was evident. In general, the effects in the infrared spectral band were opposite to those in the visible bands, due to the fact that in the infrared the reflectance and transmittance of a green leaf are high and absorptance is very small. There was a marked effect of nitrogen on infrared reflectance factors in both crops throughout the season.

In field trial 116, in 1983, treatment effects of two nitrogen levels for two sowing dates are illustrated in Fig. 3. The shift in response due to sowing date again was evident. On most dates there was a negative nitrogen effect in the visible bands (mostly small in absolute value). Throughout the season there was a positive nitrogen effect on infrared reflectance factors in crops belonging to both sowing dates. In the late-sown crop the nitrogen effect was less pronounced than in the early-sown crop.

In addition to these effects, the influence of soil moisture content at the beginning of the season in 1983 is noteworthy. Contrary to 1982, in 1983 soil moisture content 
J. G. P. W. CLEVERS

a GREEN REFL. (\%) FIELD TRIAL 116 in 1982

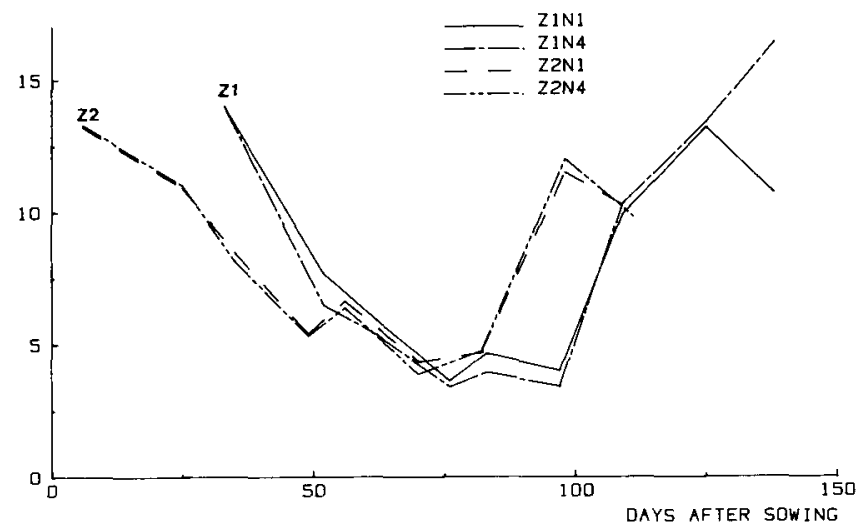

b
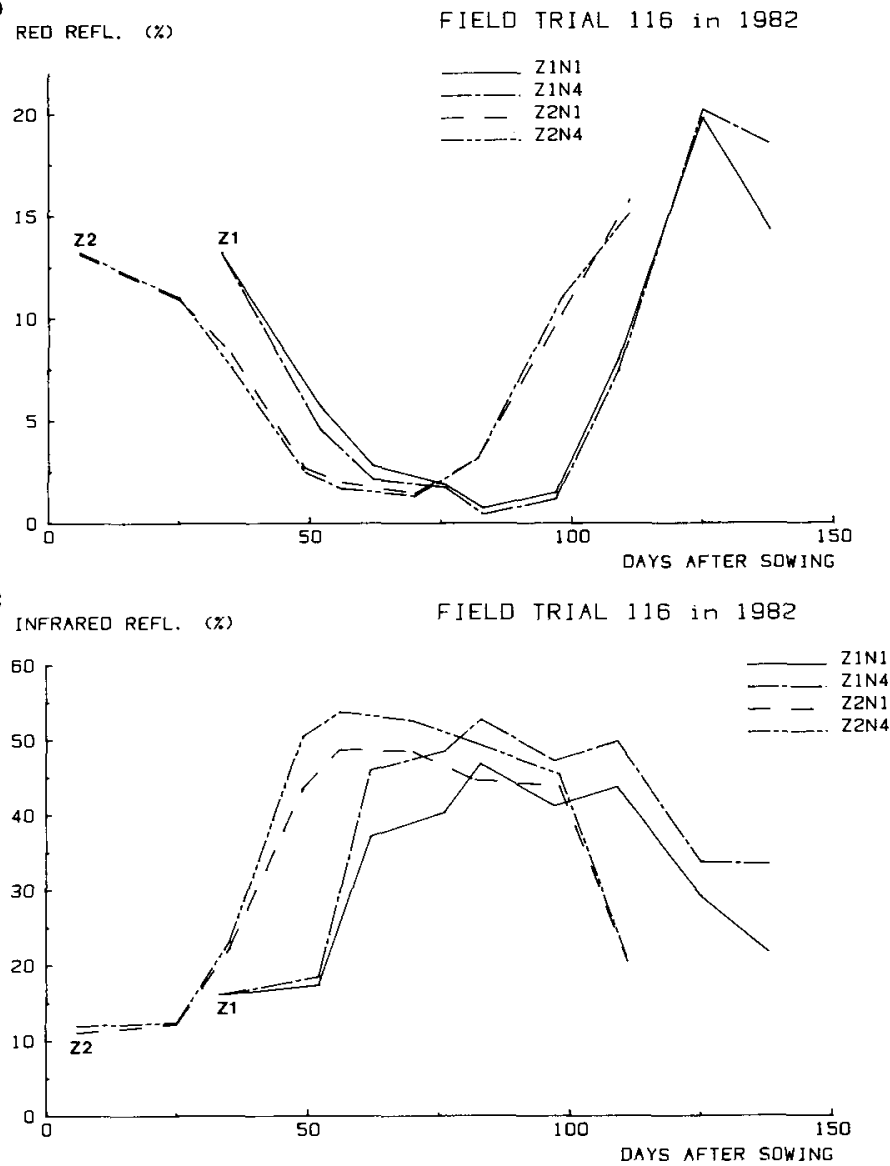

Fig. 2. Seasonal change in (a) green, (b) red and (c) infrared reflectance factors for two sowing dates $(\mathrm{Z} 1=26 \mathrm{March}$ and $\mathrm{Z} 2=22 \mathrm{April})$ and for two nitrogen levels (N1 and N4). Field trial 116 in 1982. First recording date was 28 April 1982. 
a

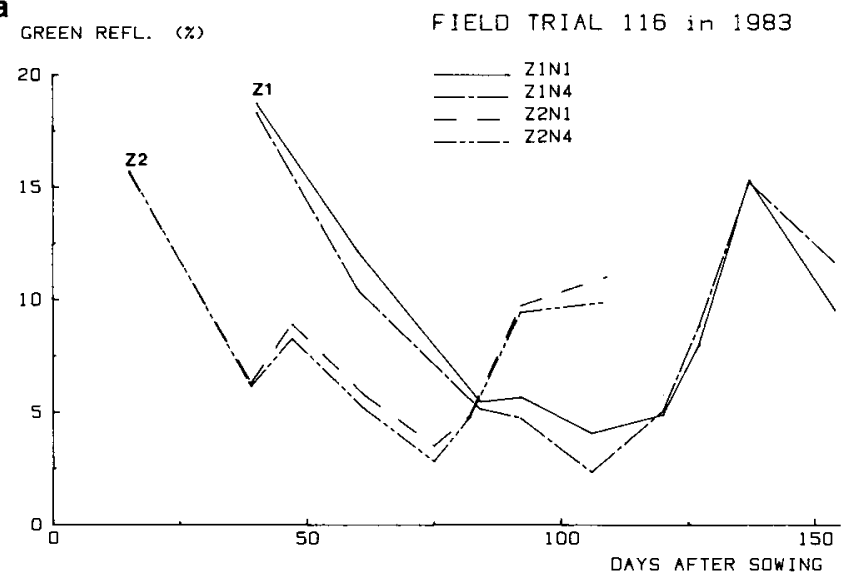

b
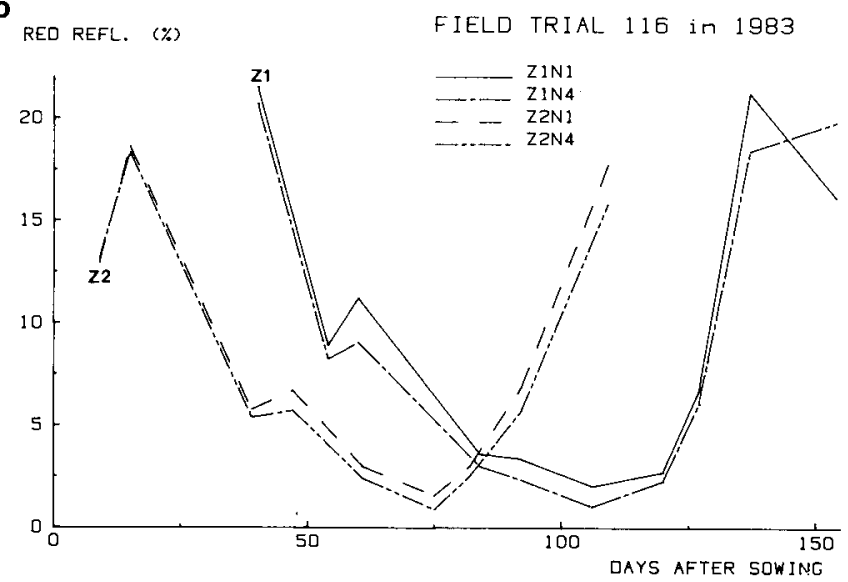

C

INFRARED REFL. (\%) FIELD TRIAL 116 in 1983

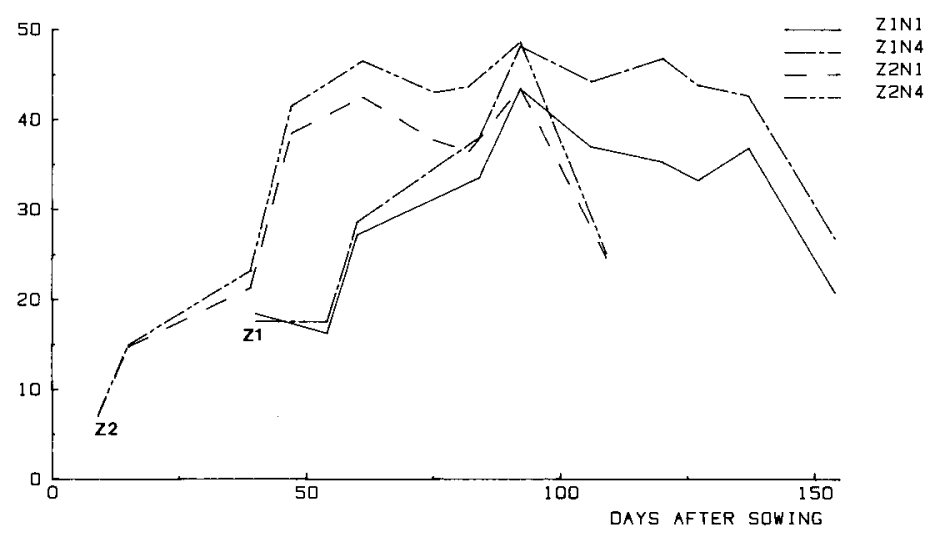

Fig. 3. Seasonal change in (a) green, (b) red and (c) infrared reflectance factors. Field trial 116 in 1983. $\mathrm{Z} 1=7$ March and $\mathrm{Z} 2=21$ April. First recording: 16 April for Z1 and 30 April for Z2. 
varied strongly between recording dates at the beginning of the growing season with incomplete soil cover. The influence of soil moisture content on reflectance was the same for all three spectral bands. Reflectance factors were relatively small at high soil moisture content of the top soil (30 April: 54 and 9 days after sowing for the early (Z1) and late (Z2) sown crop, respectively (for the green reflectance no measurements were obtained on this date); and 30 may: 84 and 39 days after sowing for the early and late sown crop, respectively) and large at low soil moisture content (16 April and 6 May) (see Fig. 3 in relation to Fig. 4).

Finally, the decrease in reflectance towards the end of the growing season for the green and red spectral bands in the early-sown crop should be mentioned. This occurred for both the green and red reflectance factors with the same treatments, which almost rules out inaccuracies in measurement as the sole explanation. Moreover, the same phenomenon could be observed in field trial 116 in 1982 (Fig. 2). Probably an increased influence of soil background because of the wilting and even the dropping of dead leaves at the end of the growing season was responsible for this decrease in reflectance.

Both in field trials 116 in 1982 and in 1983, effects of nitrogen nutrition were most pronounced for the infrared reflectance factors. In general, Clevers (1986b) showed that treatment effects could be ascertained with larger power, i.e. greater probability that the null hypothesis (that the treatment has no effects, cf. Section 'Analysis of variance') will be rejected, by means of the infrared reflectance factor. Therefore, only results for the infrared reflectance factor will be presented for field trial 92 in 1982.

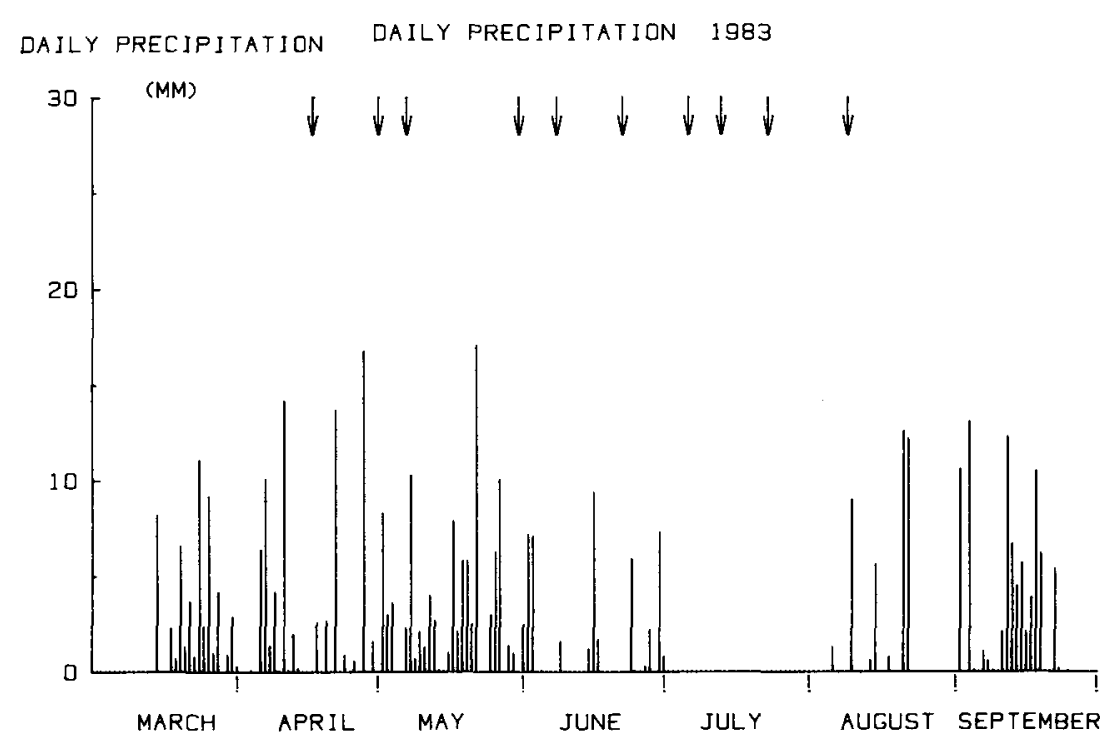

Fig. 4. Daily precipitation for the 1983 growing season. 11-31 July: no rainfall data, because of computer failure. Days of missions are indicated by arrows. 


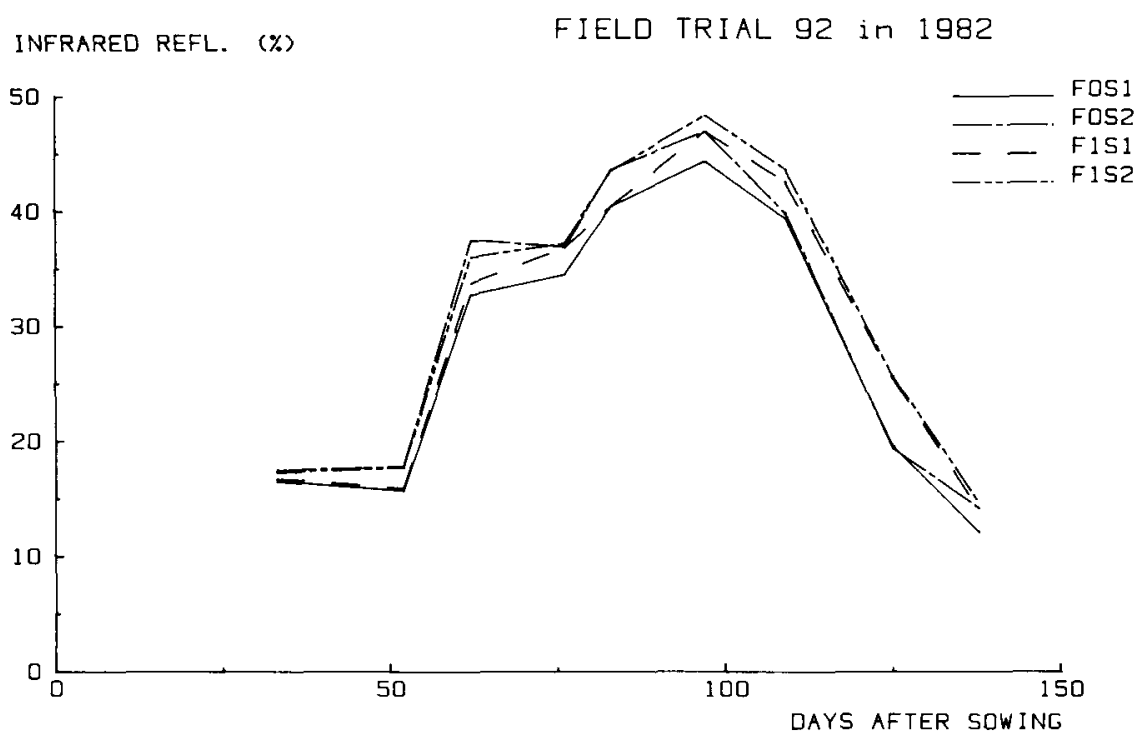

Fig. 5. Seasonal change in infrared reflectance factor as a function of fungicide treatment (F0 and F1) for two plant densities (S1 and S2). Field trial 92 in 1982.

Treatment effects for plots with and without fungicide treatment and for two sowing densities in field trial 92 in 1982 are illustrated in Fig. 5. Clevers (1986) has shown that the effect of the fungicide treatment in this field trial was significant, positive, at the end of the growing season. The sowing density effect, in general, was evident up to the end of the growing season and then was overruled by the fungicide treatment effect.

\section{Estimation of LAI}

For estimating LAI the growing season was subdivided into two stages: vegetative and generative. For the vegetative stage a corrected infrared reflectance factor was calculated by subtracting the contribution of the soil from the measured reflectance factors as described by Clevers (1986b). This is called the corrected infrared reflectance factor because it is the infrared reflectance factor one would have obtained with a black (or non-reflective) background. Clevers showed that it can be ascertained by taking the difference between measured infrared and red reflectance factors. At the end of the growing season, annual agricultural plants will show signs of senescence. Leaves turn from green to yellow. For cereals this matches the generative stage. Because leaves change colour, the reflectance factors in the visible bands will increase. This means a return to a situation comparable with an increasing contribution from the soil. During senescence the infrared reflectance factor will decrease (in a manner comparable with the influence of bare 


\section{J. G. P. W. CLEVERS}

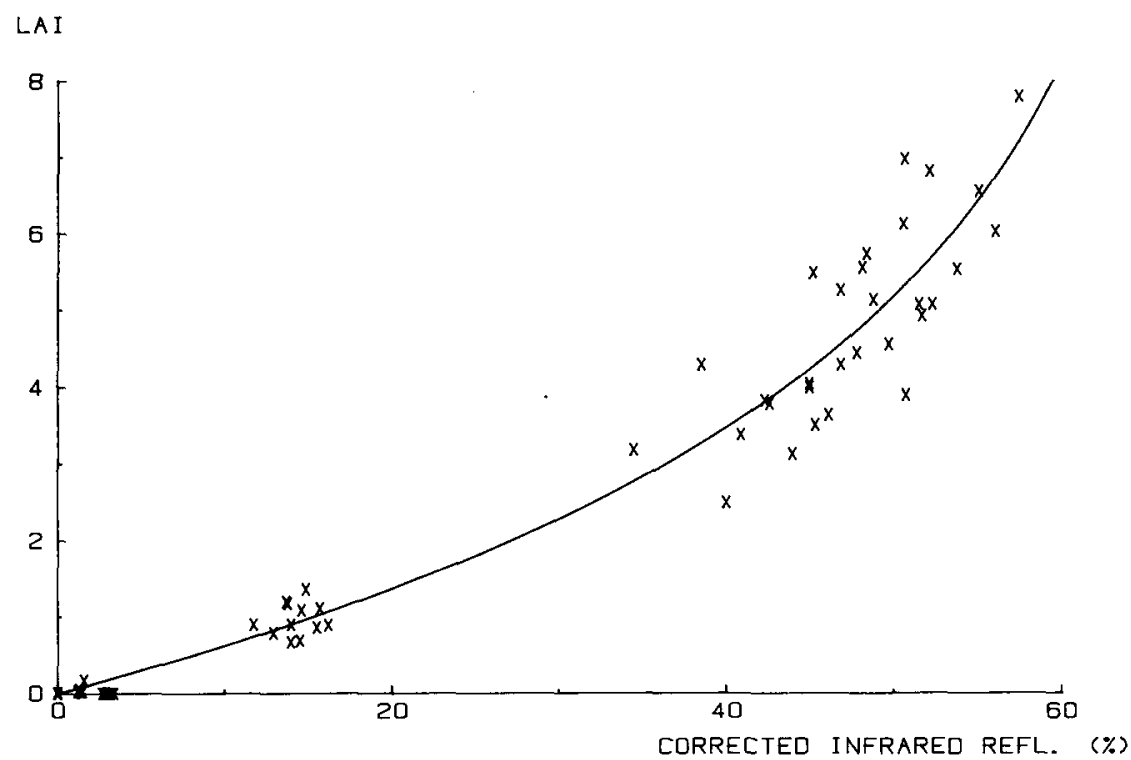

Fig. 6. Regression of LAI on corrected infrared reflectance factor applying least squares. Field trial 116, vegetative stage, 1982.

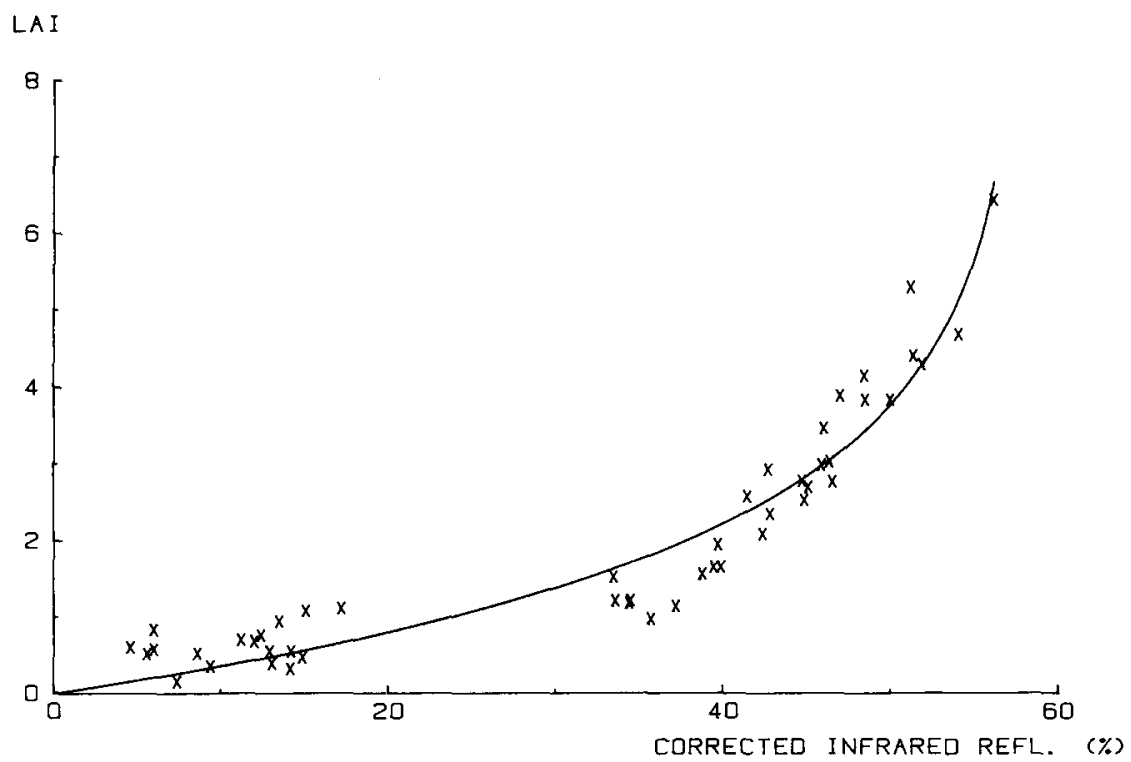

Fig. 7. Regression of LAI on corrected infrared reflectance factor applying least squares. Field trial 116, generative stage, 1982. 
soil). Clevers has shown that for the generative stage also the difference between measured infrared and red reflectance factors may be used for ascertaining a corrected infrared reflectance factor.

For estimating LAI, first of all the corrected infrared reflectance factor was calculated. Subsequently this corrected infrared reflectance factor was used for estimating LAI according to the inverse of a special case of the Mitscherlich function. For the latter regression, two parameters had to be estimated, which are different in the two stages. The inversion problem was solved in an empirical way. For the vegetative and the generative stages the regression of LAI on corrected infrared reflectance factor was described well in all field trials by using this function. This is illustrated in Figs 6 and 7 (see Clevers, 1986b, for details). In practice, the regression function of LAI on corrected infrared reflectance factor can be established by analysing a training set of a few (additional) plots, in which both reflectance factors and LAI are ascertained. Subsequently, this regression function can be applied for estimating LAI in an entire field trial (Clevers, 1986b).

Results for field trial 116 in 1983 were analysed further since soil moisture content varied significantly during the beginning of the growing season (see Fig. 4). Results of the corrected infrared reflectance factor are given in Fig. 8. The influence of soil moisture content at the beginning of the growing season has been eliminated (cf. red and infrared reflectance factors in Fig. 3). The results for the estimated LAI by using the corrected infrared reflectance factor are illustrated in Fig. 9. The same remarks about treatment effects are valid as for the infrared reflectance factor in field trial 116 in 1983 . These results are reasonably in agreement with results of the

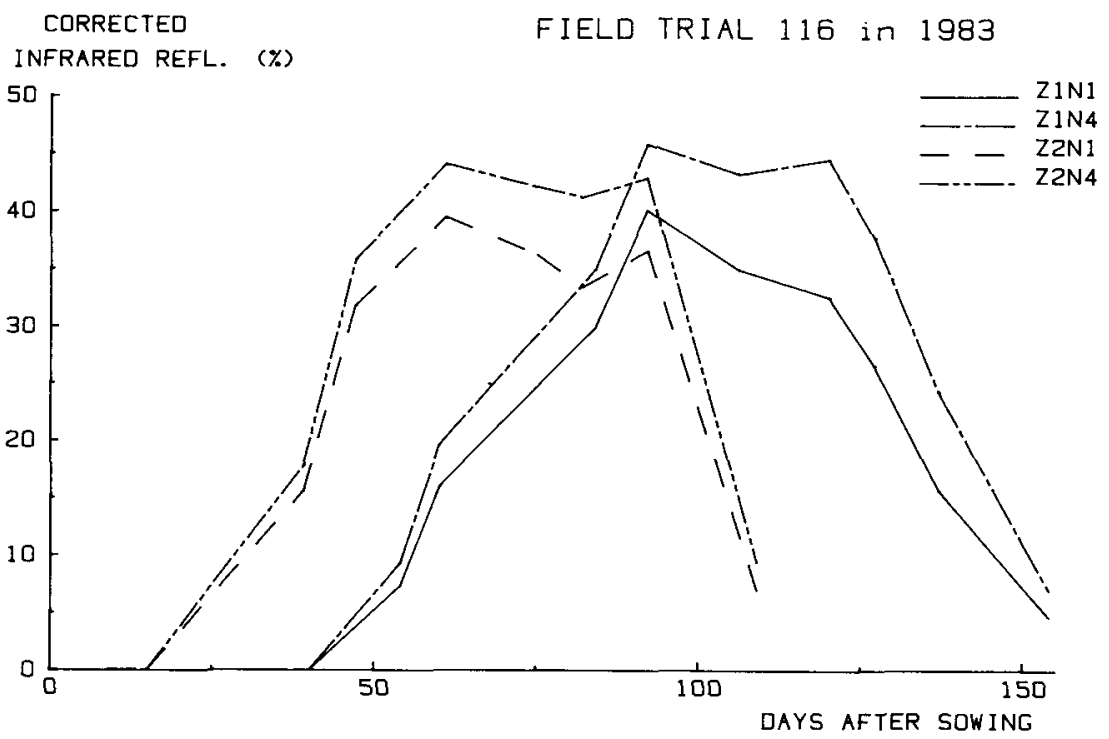

Fig. 8. Seasonal change in corrected infrared reflectance factor for field trial 116 in 1983 (cf. Fig. 3). 
EST IMATED LAI

FIELD TRIAL 116 in 1983

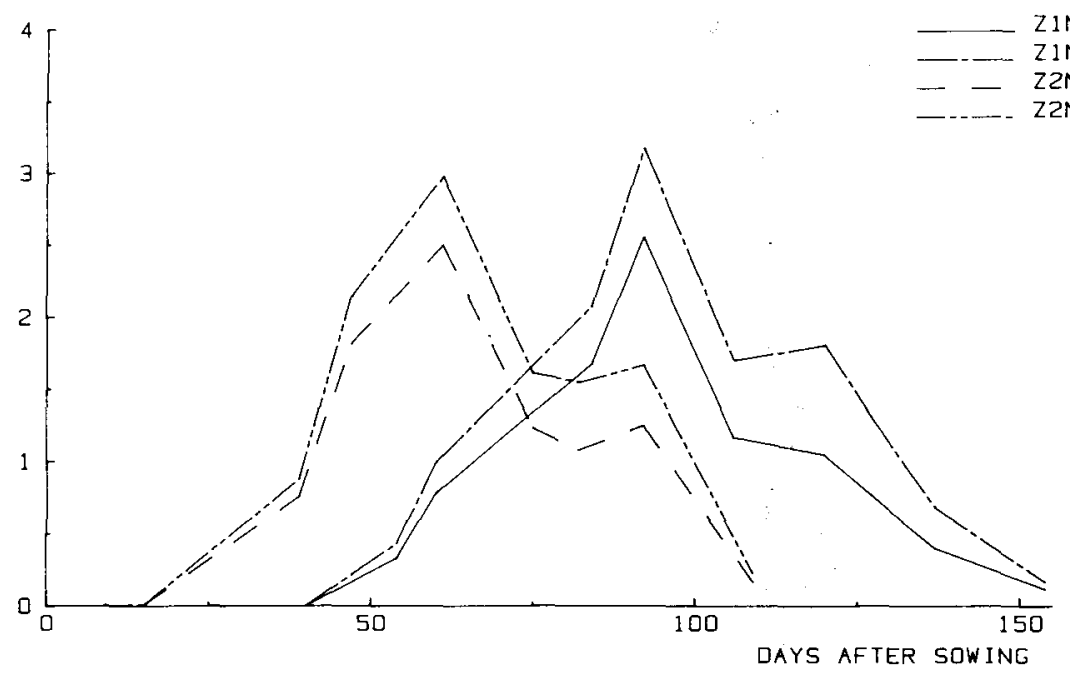

Fig. 9. Seasonal change in estimated LAI for field trial 116 in 1983.

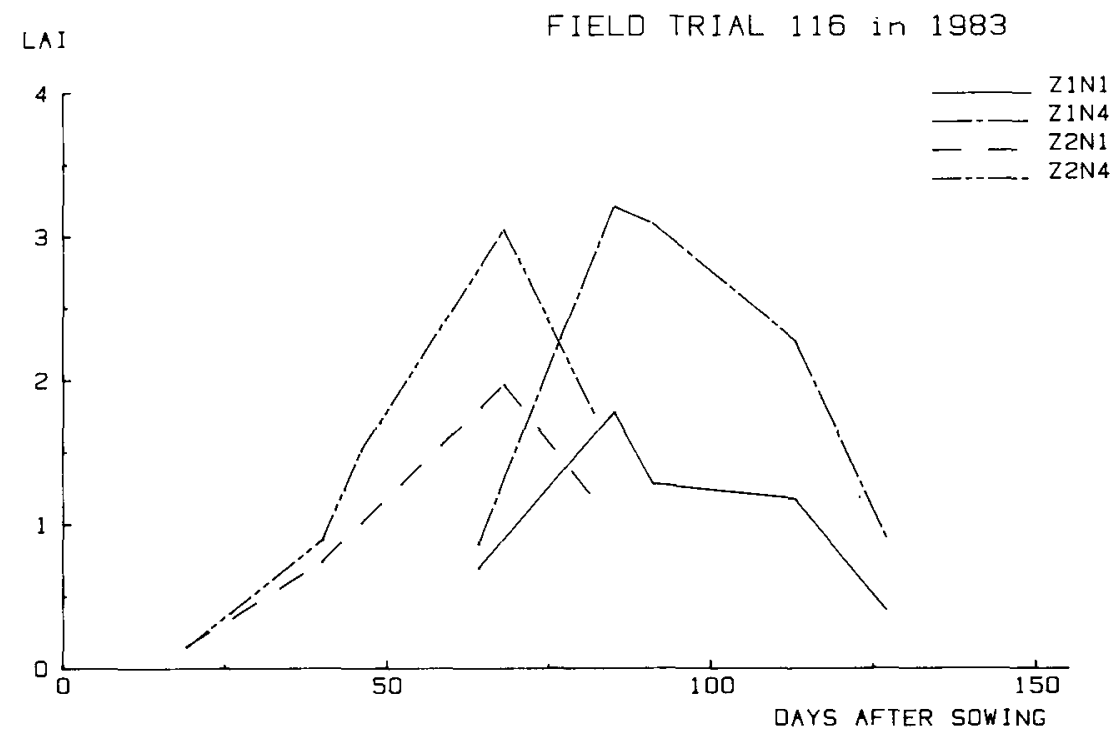

Fig. 10. Seasonal change in measured LAI (field measurements) for field trial 116 in 1983. 
LAI as measured in the field by harvesting plants $\left(0.13 \mathrm{~m}^{2}\right)$ (Fig. 10). However, at some dates quite some discrepancies between estimated and measured LAI occurred. This can largely be explained by the large variability within the LAI measured in the field (cf. Section 'Analysis of variance'). The snag is that the regression of more accurate remote sensing measurements on inaccurate field measurements is ascertained, which is contrary to most conventional calibration problems.

\section{Analysis of variance}

A very important analysis of field measurements from agricultural field trials is an analysis of variance in order to investigate whether treatment effects are significant and whether interactions (meaning that the effects of one factor are dependent on the levels of another factor, so that they are not merely additive) occur. Analogously with field measurements, an analysis of variance was carried out on the estimated LAI from reflectance factors.

Table 1 lists the means, estimated coefficients of variation (CV) of residuals and the critical levels in testing for treatment effects, for the LAI (field measurement) in field trial 116 in 1983. The variance was determined by means of appropriate averaging of inter-plot and intra-plot variances. The $\mathrm{CV}$ is the ratio of the square root of the mean squares of residuals and the mean value of the dependent variable. The critical level (often called $P$-value) is the smallest level of significance at which the observed result would just lead to rejection of the null hypothesis (that a treatment has no effects). On 31 May and 6 June the interaction effect between sowing date and nitrogen nutrition was significant at the $5 \%$ level. The sowing date effect and the nitrogen nutrition effect were significant on most dates. The large critical level for sowing date effect on 6 June was caused by the fact that the late-sown crop had a smaller LAI than the early-sown crop at the beginning of the season and caught up with the early-sown crop at the beginning of June, resulting in a larger LAI for the late-sown crop at the end of the season. Coefficients of variation were quite large.

Results of the analysis of variance for the estimated LAI from reflectance measurements in field trial 116 in 1983 are listed in Table 2. On most dates, critical levels in testing for treatment effects by means of the estimated LAI were smaller than those obtained from field measurements of LAI (Table 1). This applied in particular to the nitrogen nutrition effect. The large critical level for sowing date effect on 5 July was caused by similar reflectance factors per band for both sowing dates at the end of June and at the beginning of July, resulting in similar LAI estimates and no effect of sowing date. Also the variability (CV values) of estimated LAI was much smaller than variability of measured LAI. Results for April are not listed, because bare soil predominated on that date.

\section{Estimation of other plant characteristics}

One aspect that needs further study in the near future is whether one should try to estimate LAI by means of reflectance measurements or whether one should look for some other plant characteristic in order to obtain information about crop growth 
Table 1. LAI: means, CVs and critical levels in testing for treatment effects, obtained on consecutive sampling dates. Field trial 116 in 1983.

\begin{tabular}{llllll}
\hline Date & Mean & CV & \multicolumn{2}{l}{ Critical level in testing } \\
\cline { 3 - 6 } & & & interaction & sowing dates & nitrogen nutrition \\
10 May & 0.54 & 0.420 & 0.283 & 0.003 & 0.208 \\
31 May & 1.91 & 0.353 & 0.010 & 0.030 & 0.001 \\
6 June & 1.96 & 0.288 & 0.008 & 0.356 & 0.002 \\
28 June & 2.18 & 0.272 & 0.980 & 0.018 & 0.007 \\
12 July & 1.09 & 0.338 & 0.788 & 0.001 & 0.007 \\
\hline
\end{tabular}

Table 2. LAI estimated by reflectance measurements: means, CVs and critical levels in testing for treatment effects, obtained on consecutive missions. Field trial 116 in 1983.

\begin{tabular}{llllll}
\hline Date & Mean & CV & \multicolumn{2}{l}{ Critical level in testing } \\
\cline { 3 - 6 } & & & interaction & sowing dates & nitrogen nutrition \\
6 May & 0.47 & 0.056 & 0.000 & 0.000 & 0.000 \\
30 May & 1.43 & 0.120 & 0.110 & 0.002 & 0.001 \\
7 June & 2.54 & 0.090 & 0.231 & 0.000 & 0.002 \\
21 June & 2.13 & 0.109 & 0.030 & 0.001 & 0.000 \\
5 July & 1.46 & 0.089 & 0.001 & 0.944 & 0.000 \\
12 July & 1.21 & 0.080 & 0.284 & 0.010 & 0.000 \\
22 July & 1.01 & 0.080 & 0.156 & 0.000 & 0.000 \\
8 August & 0.16 & 0.113 & 0.051 & 0.022 & 0.000 \\
\hline
\end{tabular}

or condition. Remote measurements of reflectance factors do not concern leaves only. Stems and ears, for instance, will also contribute to the measured reflectance factor. It is true that in most crops the leaves contribute the most to the measured reflectance factor. But the agronomist is not primarily interested in the LAI. He is more interested in the photosynthetic activity or light interception and its result: the final yield of some plant part. For pinpointing the cause of differences in yield he may also need information about the crop during the growing season. Photosynthetic activity is difficult to measure in the laboratory and it takes too much time and effort to measure it for plots in a field trial. The same applies to light interception. Therefore the agronomist has usually resorted to the LAI (since photosynthesis takes place primarily in the green leaves), or to dry matter weight. Remote sensing techniques offer new sorts of information about crops, and therefore in future agronomists may decide to use new plant characteristics that are more important than those currently used today.

If one is interested in plant characteristics other than LAI - such as dry matter content, the content of some nutrient (chemical analysis) or the mutual proportions of different plant parts, none of which can be ascertained directly by means of remote sensing techniques - one has to take samples in the field. However, the vari- 
ability per plant of, e.g., some chemical component, is much smaller than the variability of LAI or dry matter weight per plant. It is possible to ascertain the content of such a component with great precision by harvesting only a few plants. However, if one wishes to ascertain the total amount of some nutrient in the plants, one has to incorporate total fresh or dry matter weight into the calculations. These characteristics show a much larger variability within a plot (from plant to plant). If total fresh or dry matter weight correlate well with LAI, they may be ascertained more precisely, even though more indirectly, by means of reflectance measurements.

The best procedure if one is interested in this more detailed information will be to estimate LAI and fresh or dry matter weight by means of reflectance measurements and subsequently to ascertain plant composition by harvesting a few plants at random. In this way, aerial photography may act as an important supplemental technique in agricultural research.

\section{Conclusions}

1. Black and white multispectral aerial photography (MSP) is an appropriate technique for the frequent acquirement of remotely sensed data in agricultural research.

2. Reflectance factors obtained by MSP could be used for ascertaining differences in crop response caused by different treatments. Results for reflectance factors were consistent when comparing results of successive growing seasons. The reflectance factors in an infrared band were particularly outstanding for ascertaining treatment differences.

3. If LAI was estimated by reflectance factors, by using a regression curve of LAI on corrected infrared reflectance factor, the critical levels in testing for treatment differences were in general smaller than those for the measured LAI of samples, indicating a larger power for the estimated LAI. This also applied to the coefficients of variation.

\section{References}

Bunnik, N. J. J., 1978. The multispectral reflectance of shortwave radiation by agricultural crops in relation with their morphological and optical properties. Thesis. Mededelingen Landbouwhogeschool Wageningen 78-1, $175 \mathrm{pp}$.

Clevers, J. G. P. W., 1986a. Multispectral aerial photography yielding well calibrated reflectance factors with high spectral, spatial and temporal resolution for crop monitoring. Proceedings Third International Colloquium on Spectral Signatures of Objects in Remote Sensing, Les Arcs, France, ESA SP-247: 343-346.

Clevers, J. G. P. W., 1986b. Application of remote sensing to agricultural field trials. Thesis. Agricultural University Wageningen Papers $86-4,227 \mathrm{pp}$.

Curran, P. J., 1980. Relative reflectance data from preprocessed multispectral photography. International Journal of Remote Sensing 1: 77-83.

Curran, P. J., 1982. Multispectral photographic remote sensing of green vegetation biomass and productivity. Photogrammetric Engineering and Remote Sensing 48: 243-250.

Curran, P. J., 1983. Estimating green LAI from multispectral aerial photography. Photogrammetric Engineering and Remote Sensing 49: 1709-1720. 


\section{J. G. P. W. CLEVERS}

Graham, R., 1980. The ITC multispectral camera system with respect to crop prognosis in winter-wheat. ITC Journal 1980-2: 235-254.

Kannegieter, A., 1980. An experiment using multispectral photography for the detection and damage assessment of disease infection in winter-wheat: Agronomic considerations. ITC Journal 1980-2: 189234.

Large, E. C., 1954. Growth stages in cereals. Illustration of the Feekes scale. Plant Pathology 3: 128129.

Ross, D. S., 1973. Atmospheric effects in multispectral photographs. Photogrammetric Engineering 39 377-384.

Sievers, J., 1976. Zusammenhänge zwischen Objectreflexion und Bildschwärzung in Luftbildern. Bayerischen Akademie der Wissenschaften, München, Reihe C: Dissertationen, Heft. Nr. 221, 129 pp.

Slater, P. N., 1980. Remote sensing: optics and optical systems. Addison-Wesley Publ. Comp., Reading, Massachusetts, $575 \mathrm{pp}$.

Verhoef, W. \& N. J. J. Bunnik, 1975. A model study on the relation between crop characteristics and canopy spectral reflectance. Niwars Publ. 33, 89 pp. 